\title{
Rapidly Progressing to ESRD in an Individual with Coexisting ADPKD and Masked Klinefelter and Gitelman Syndromes
}

\author{
Ramón Peces ${ }^{1,+}+{ }^{\circ}$, Carlos Peces $^{2}$, Rocío Mena ${ }^{3}$, Emilio Cuesta ${ }^{4}$, Fe Amalia García-Santiago ${ }^{3,5,6} \oplus^{\circ}$, \\ Marta Ossorio ${ }^{1}$, Sara Afonso ${ }^{1}$, Pablo Lapunzina ${ }^{3,5,6} \mathbb{i}$ and Julián Nevado $3,5,6, *,+\mathbb{D}$ \\ 1 Servicio de Nefrología, Hospital Universitario La Paz, IdiPAZ, Universidad Autónoma, 28046 Madrid, Spain; \\ rpecser@gmail.com (R.P.); marta.ossorio@salud.madrid.org (M.O.); sara.afonso@salud.madrid.org (S.A.) \\ 2 Area de Tecnología de la Información, SESCAM, 45071 Toledo, Spain; carlos.peces@sescam.jccm.es \\ 3 Instituto de Genética Médica y Molecular (INGEMM), Hospital Universitario La Paz, IdiPAZ, \\ Universidad Autónoma, 28046 Madrid, Spain; mariarocio.mena@salud.madrid.org (R.M.); \\ feamalia.garcia@salud.madrid.org (F.A.G.-S.); plapunzina@gmail.com (P.L.) \\ 4 Servicio de Radiología, Hospital Universitario La Paz, IdiPAZ, Universidad Autónoma, 28046 Madrid, Spain \\ emilio.cuesta@salud.madrid.org \\ 5 CIBERER, Centro de Investigación Biomédica en Red de Enfermedades Raras, ISCIII, 28046 Madrid, Spain \\ 6 ITHACA, European Reference Network, Hospital Universitario La Paz, IdiPAZ, Universidad Autónoma, \\ 28046 Madrid, Spain \\ * Correspondence: jnevado@salud.madrid.org; Tel.: +34-917-277-151; Fax: +34-917-277-382 \\ + These authors contributed equally to this work.
}

check for updates

Citation: Peces, R.; Peces, C.; Mena, R.; Cuesta, E.; García-Santiago, F.A.; Ossorio, M.; Afonso, S.; Lapunzina, P.; Nevado, J. Rapidly Progressing to ESRD in an Individual with

Coexisting ADPKD and Masked Klinefelter and Gitelman Syndromes. Genes 2022, 13, 394. https:/ / doi.org/ 10.3390 /genes 13030394

Academic Editor: Manuela Priolo

Received: 14 January 2022

Accepted: 18 February 2022

Published: 23 February 2022

Publisher's Note: MDPI stays neutral with regard to jurisdictional claims in published maps and institutional affiliations.

Copyright: (c) 2022 by the authors. Licensee MDPI, Basel, Switzerland. This article is an open access article distributed under the terms and conditions of the Creative Commons Attribution (CC BY) license (https:/ / creativecommons.org/licenses/by/ $4.0 /)$.

\begin{abstract}
Autosomal dominant polycystic kidney disease (ADPKD) is the most common monogenetic hereditary renal disease, promoting end-stage renal disease (ESRD). Klinefelter syndrome (KS) is a consequence of an extra copy of the $\mathrm{X}$ chromosome in males. Main symptoms in KS include hypogonadism, tall stature, azoospermia, and a risk of cardiovascular diseases, among others. Gitelman syndrome (GS) is an autosomal recessive disorder caused by SLC12A3 variants, and is associated with hypokalemia, hypomagnesemia, hypocalciuria, normal or low blood pressure, and salt loss. The three disorders have distinct and well-delineated clinical, biochemical, and genetic findings. We here report a male patient with ADPKD who developed early chronic renal failure leading to ESRD, presenting with an intracranial aneurysm and infertility. NGS identified two de novo PKD1 variants, one known (likely pathogenic), and a previously unreported variant of uncertain significance, together with two SLC12A3 pathogenic variants. In addition, cytogenetic analysis showed a 47, XXY karyotype. We investigated the putative impact of this rare association by analyzing possible clinical, biochemical, and/or genetic interactions and by comparing the evolution of renal size and function in the proband with three age-matched ADPKD (by variants in PKD1) cohorts. We hypothesize that the coexistence of these three genetic disorders may act as modifiers with possible synergistic actions that could lead, in our patient, to a rapid ADPKD progression.
\end{abstract}

Keywords: ADPKD; apoptosis; chronic kidney disease progression; fibrosis; Gitelman syndrome; intracranial aneurysm; Klinefelter syndrome

\section{Introduction}

Autosomal dominant polycystic kidney disease (ADPKD) is mainly caused by mutations in two main genes, PKD1 (OMIM\#: 601313) and PKD2 (OMIM\#: 173910) [1,2]. It is characterized by renal, progressive, age-related, fluid-filled cyst development, promoting ESRD [3,4]. It is widely known that phenotype variability is highly associated with the mutated gene (PKD1 variants versus PKD2 variants), and the type of the variant (frameshift/nonsense versus non-truncating variants) [5]. However, the existence of several modulator genes, and the existence of hypomorphic alleles may also largely affect the clinical features of ADPKD [5-12], including extra-renal clinical manifestations such as hepatic cysts, hernias, mitral valve prolapse, and intracranial aneurysms $[3,4]$. The renal 
disease progression of ADPKD involves not only cystogenesis, but also the activation of inflammatory and fibrotic pathways as a consequence of endothelial dysfunction $[13,14]$. Indeed, ADPKD, as a single gene disorder, is associated with numerous signaling cascades and reactions involved in cellular polarity, proliferation, fibrosis, and apoptosis [13-15]. Klinefelter syndrome (KS) is the most common genetic cause of infertility, and is the most variable aneuploidy $(0.15 \%$ of the general population), showing high phenotypic variability and comorbidities. It is one of the common sex chromosome disorders in men. Interestingly, approximately $64 \%$ of these cases were undiagnosed throughout life [16,17]. A non-disjunction of paired X-chromosomes during the first or second meiotic division [17] may contribute to its origin, and is equally due to a paternal/maternal meiotic missegregation event. KS clinical manifestations were associated with increased risk for mitral valve prolapse, pulmonary embolism, aortic valvular disease, autoimmune diseases, the rupture of the berry aneurysms, lower-extremity varicose veins, deep vein thrombosis, venous stasis ulcers, type II diabetes mellitus and metabolic syndrome [18-21], extra-gonadal germ cell tumors and non-Hodgkin lymphoma [22], a 20-fold-higher risk of developing breast cancer, and osteoporosis. KS patients also have hypogonadism, which may increase the risk of atherogenesis [18]. However, the molecular mechanisms underlying the KS phenotype have not been clearly understood yet, although both genetic and epigenetic effects, due to the supernumerary X-chromosome, seem to contribute to this pathological pattern [23-26]. Gitelman syndrome (GS, OMIM \#263800) is a rare autosomal recessive disorder due to homozygous or compound heterozygous variants in the SLC12A3 gene which encodes the thiazide-sensitive $\mathrm{Na}^{+} / \mathrm{Cl}^{-}$cotransporter. GS is clinically characterized by hypomagnesemia, hypochloremic metabolic alkalosis, hypokalemia, hypereninemia, and hyperaldosteronism with normal or low blood pressure and salt loss [27]. Most of patients with GS present during childhood or early adulthood, however, it has high clinical variability, and some patients may not have GS features [27-31]. We here report a patient with ADPKD and coexisting masked KS and GS, based on genetic studies and clinical features. Although the three disorders may have different genetic, biochemical, and clinical findings, it is possible that the overlapping findings have influenced each other. We investigated the possibility that this fact may be a consequence of putative genetic interactions and/or additive or synergistic effects through the different signaling pathways.

\section{Materials and Methods}

\subsection{Follow-Up Study}

We compared the clinical evolution of ADPKD in the proband with our three control PKD1 defined cohorts by kidney magnetic resonance imaging (MRI) [32] and estimated glomerular filtration rate (eGFR) studies. To this end, total kidney volume (TKV), height adjusted total kidney volume (htTKV), and eGFR were determined. The eGFR was determined by the chronic kidney disease epidemiology collaboration (CKD-EPI) equation using the serum creatinine and the serum cystatin $C$ values calculated using the formula: eGFRCysC $=77.24 \times\left(\mathrm{Cys}^{-1.2623}\right)$. Mayo clinic imaging classification and the prediction of future eGFR based on the classification were determined in the proband [33].

\subsection{Genetics Analysis}

\subsubsection{ADPKD by MLPA Analysis}

ADPKD gross deletion analysis was made by means of multiplex ligation-dependent probe amplification (MLPA) using the SALSA MLPA KIT P351/P352 for PKD1/PKD2 (MRC-Holland, Amsterdam, The Netherlands), following the manufacturer's instructions. Data analysis was done with Coffalyser v6 MLPA Analysis Software (MRC-Holland).

\subsubsection{Massive Parallel Sequencing Analysis}

Massive parallel sequencing analysis was performed with a custom-targeted nextgeneration sequencing (NGS) gene panel (Nefroseq v1.2) designed for the study of the full spectrum of genetic nephropathies (which includes 380 genes related to kidney dis- 
eases) [34]. The sequence was captured using SeqCap EZ technology (Roche Nimblegen. Madison, WI, USA) and subsequently ran on a Hiseq4000 (Illumina. San Diego, CA, USA). Bioinformatics analysis was performed in-house by using publicly available software tools (trimmomatic-0.32; Bowtie2 v2.1.0; Picard-tools v1.27; Samtools v0.1.19-44428cd; Bedtools v2.26.0; Genome Analysis TK v3.3-0 y SnpE 4.11; ClinVar date 20140703 dbscSNV1.1 dbNSFP version 3.0 dbSNP v138), and simultaneously with variant Caller V2.1 tool (Illumina). In silico pathogenicity prediction was analyzed using Alamut 2.7 (interactive Biosoftware, Rouen, France) and others such as SIFT Ensembl 66; Polyphen-2 v2.2.2; Mutation Assessor, release 2; FATHMM, v2.3; Gerp2; PhyloP; CADD, v1.3. Population frequencies of the detected variants were assessed using the Exome Aggregation Consortium (ExAC; Exac r0.3) data; 1000 genome project; Spanish Exon Variant Project; NHLBI exome sequencing project: ESP6500_EA_AF). After the filtering of the relevant variants, validation of the candidate variants in the patient and parents was carried out through traditional Sanger Sequencing (see below). In parallel to the analysis process, exhaustive quality control of the sequenced samples was performed according to a custom pipeline (a suite of QC scripts that facilitate data quality assessment), available upon request. Classification and interpretation of the variants were made according to the American College of Medical Genetics and Genomics (ACMG) guidelines.

\subsubsection{Sanger Sequencing}

PKD1 mutation screening for coding sequences and intron/exon boundaries for exons 27 and 29 were confirmed by Long Range-PCR and direct sequencing. SLC12A3 mutation screening for coding sequences and intron/exon boundaries for exons 16 and 25 was performed by PCR and direct sequencing. PCR conditions and primers (designed with the help of Primer3 plus v04.0 Software) are available upon request. PCR products were sequenced using BrightDye Terminator cycle kit (Nimagen, Nijmegen, The Netherland) and run on an ABI3730XL Sequencer (Thermo Fisher, Waltham, MA, USA).

\subsubsection{Azoospermia Studies}

Our pipeline routine for azoospermia studies includes microdeletions of the Y-chromosome, karyotyping, and cystic fibrosis analysis. The Y-chromosome microdeletions analysis was performed by standard fragment analysis, by multiplex PCR of STS markers and direct sequencing (primers are available upon request). The molecular diagnosis of Y-chromosome microdeletions was performed following the recommendations of the EAA/EMQN best practice guidelines [35]. Briefly, two multiplex PCR were carried out in each patient. Multiplex A contained primers for SRY and ZFX/ZFY genes and for AZF a, b, and c regions (sY86, sY127, and sY254, respectively). A second multiplex PCR was performed to reinforce diagnostic accuracy. This multiplex contained a second set of primers for AZF $a, b$, and c regions (sY84, sY134, and sY255, respectively), in addition to primers for SRY and ZFX/ZFY genes. In parallel to the patient's DNA sample, a DNA sample from a normal male with normal spermatogenesis and a female were used as positive and negative controls, respectively. A water sample was also run as a control for reagent contamination. Cystic fibrosis screening was made by a commercial kit of CFTR analysis (Devyser; HQ, Hägersten, Sweden). Cytogenetic analyses were performed on peripheral blood lymphocytes by GTGbanded metaphases at a resolution of about 550 bands according to standard laboratory protocol using Chromosome Kit P (Euroclone, Siziano PV, Italy). Normally, 20 metaphases were counted.

\section{Results}

\subsection{Case Presentation}

The proband, a 36 year-old male German patient presented in our outpatient clinic for renal evaluation in April 2016. He was the fourth child of unrelated and healthy parents (Figure 1A). 
A)

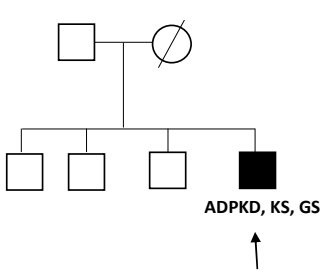

B)

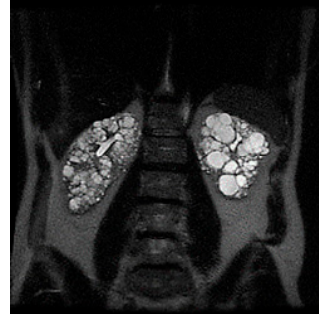

E)

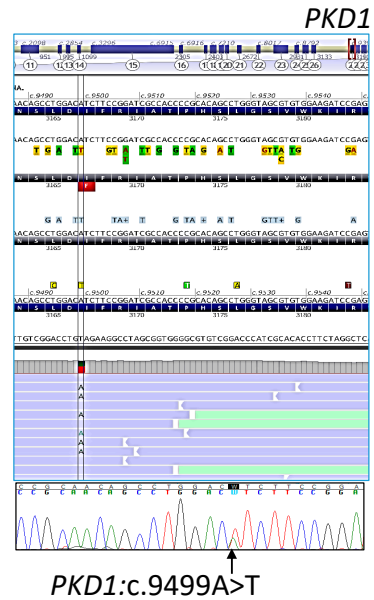

\section{variants}

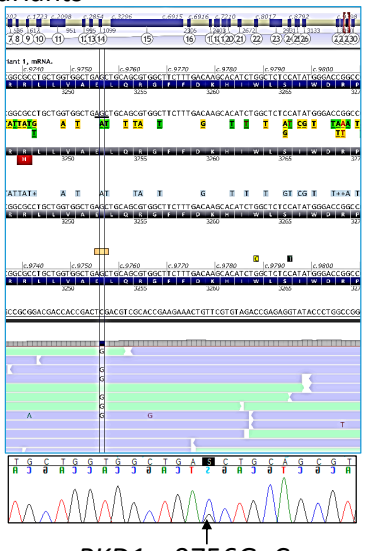

PKD1:c.9756G>C

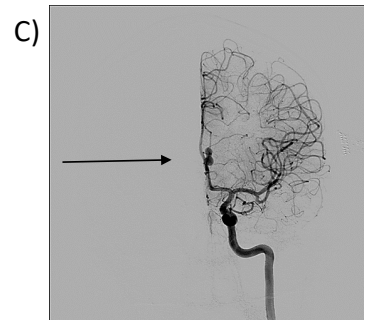

D)
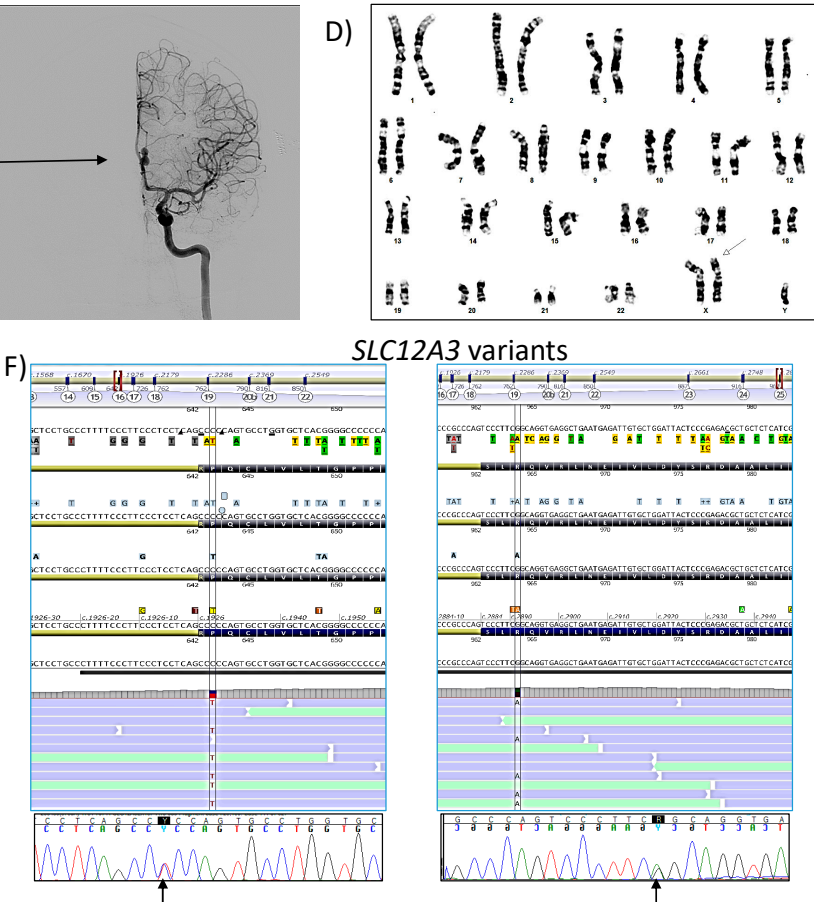

SLC12A3:C.1928C>T
SLC12A3 variants

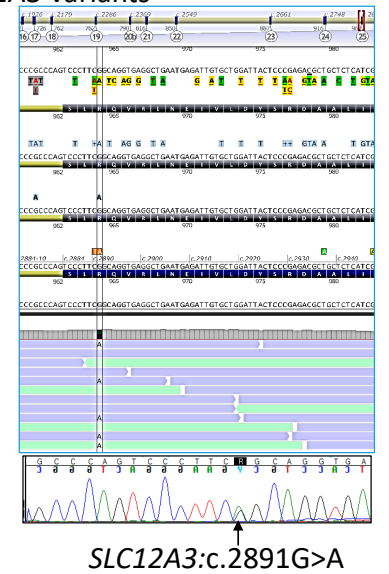

Figure 1. (A) Pedigree of the family. The proband (arrow). (B) Abdominal coronal T2 MRI of the proband at 36 years, showing a TKV of $726 \mathrm{~mL}$ (htTKV of $370 \mathrm{~mL} / \mathrm{m}$ ). (C) Cerebral angiography showing an aneurysm of the anterior communicating artery with hourglass image (arrow) (D) Cytogenetic analysis showing a 47, XXY karyotype, 50 metaphases are counted. (E) Molecular establishment of PKD1 variants in the proband: NM_001009944.3:c.9499A>T and NM_001009944.3:c.9756G>C, by NGS (top) and Sanger sequencing (bottom). (F) Molecular establishment of SLC12A3 variants in the proband: NM_0000339.3:c.1928C>T and NM_0000339.3:c.2891G>A, by NGS (top) and confirmed by Sanger sequencing (bottom). ADPKD, Autosomal dominant polycystic kidney disease; KS, Klinefelter syndrome; GS, Gitelman syndrome.

He was born after an uncomplicated pregnancy. The family history was negative for abortion and genetic abnormalities. He was diagnosed with arrhythmia at 21 , and epididymal cysts at 27 years old in Germany. At that age, abdominal ultrasonography (US) showed bilateral, enlarged, cystic, and echogenic kidneys being diagnosed with ADPKD. Surgical intervention of bilateral inguinal hernias was undertaken in Germany. At this time, the patient was also receiving intermittent treatment with Ramipril (5 mg/daily), which was finally discontinued. His serum creatinine levels were $2 \mathrm{mg} / \mathrm{dL}$ with an eGFR of $44 \mathrm{~mL} / \mathrm{min} / 1.73 \mathrm{~m}^{2}$. His father was alive at 77 years old without a history of ADPKD or any other renal disease. His mother died at the age of 51 (unrelated to genetic known cardiac/renal disorder). His three brothers were asymptomatic based on medical history. There was no history of intracranial aneurysms, ADPKD, or other renal diseases in other family members. Our first physical examination (in 2016, at 36 years old) established a well-developed male (weight, $85 \mathrm{~kg}$; height, $196 \mathrm{~cm}$; body mass index (BMI), $22.1 \mathrm{Kg} / \mathrm{m}^{2}$ ), presenting a decreased testicular volume. Blood pressure was 115/70 $\mathrm{mmHg}$ without any treatment. His serum creatinine level was $2.9 \mathrm{mg} / \mathrm{dL}$ and eGFR of $27 \mathrm{~mL} / \mathrm{min} / 1.73 \mathrm{~m}^{2}$. ECG showed a complete blockage of the right branch of the bundle of His, and abdominal MRI documented bilateral, enlarged, cystic kidneys. A TKV, $726 \mathrm{~mL}$ (right kidney $336 \mathrm{~mL}$, left kidney $390 \mathrm{~mL}$ ) and htTKV, $370 \mathrm{~mL} / \mathrm{m}$ were measured by manual segmentation using MRI [32]. We classified the patient into Mayo class 1B [33]. However, the prediction of future eGFR based on Mayo imaging classification determined and estimated ESRD at 48 years old. No liver cysts were appreciated (Figure 1B). The patient also had a saccular cerebral aneurysm of the left anterior communicating artery measur- 
ing $11 \times 5 \mathrm{~mm}$, that we established by MRI angiography and confirmed by computed tomography (CT) angiography and arteriography (Figure 1C). An intent of embolization resulted in failure, and he denied surgical intervention of the aneurysm. He was married but without offspring. Due to couple infertility, the patient also underwent urologic evaluation in our Centre, which confirmed epididymal cysts and diagnosed azoospermia. Indeed, he had increased serum luteinizing hormone $(\mathrm{LH})(24.70 \mathrm{IU} / \mathrm{L}$; normal range: 1.50-9.30 IU/L) and follicle-stimulating hormone (FSH) levels (60.12 IU/L; normal range: 1.40-18.10 IU/L) with normal prolactin (15.66 ng/mL; normal range: $2.10-17.70 \mathrm{ng} / \mathrm{mL}$ ) and total testosterone $(4.49 \mathrm{ng} / \mathrm{mL}$; normal range: $1.65-7.53 \mathrm{ng} / \mathrm{mL})$, but low free testosterone levels $(12.30 \mathrm{pg} / \mathrm{mL}$; normal range: $15.0-50.0 \mathrm{pg} / \mathrm{mL})$. His triiodothyronine (T3), thyroxin T4, and thyroid stimulating (TSH) hormones, and vitamin-D (48 ng/mL; normal range: $30-100 \mathrm{ng} / \mathrm{mL}$ ) levels were normal, but parathyroid hormone (iPTH) (levels (169 pg/mL; normal range: $18.5-88.0 \mathrm{pg} / \mathrm{mL}$ ) were increased. Bone mineral density examination also showed marked osteoporosis. A control CT cerebral angiography performed 18 months after the first observation (at 38 years old) revealed that the cerebral aneurysm of the left anterior communicating artery had increased up to $11.9 \times 5.3 \mathrm{~mm}$. At 42 years old, his serum creatinine level was $5.4 \mathrm{mg} / \mathrm{dL}$ and eGFR was $12 \mathrm{~mL} / \mathrm{min} / 1.73 \mathrm{~m}^{2}$ (Table 1). Several intents of treatment with a low dose of Telmisartan (10 mg/daily) resulted in hypotension and were discontinued.

Table 1. Evolution of electrolytes and renal function on the proband.

\begin{tabular}{|c|c|c|c|c|c|c|c|c|}
\hline $\begin{array}{l}\text { Age } \\
\text { Years }\end{array}$ & Na mmol/L & $\mathrm{K} \mathrm{mmol} / \mathrm{L}$ & $\mathrm{Cl} \mathrm{mmol} / \mathrm{L}$ & Mg mg/dL & $\begin{array}{l}\mathrm{HCO}_{3}^{-} \\
\mathrm{mmol} / \mathrm{L}\end{array}$ & $\mathrm{pH}$ & $\begin{array}{l}\text { Serum } \\
\text { Creatinine } \\
\text { mg/dL }\end{array}$ & $\begin{array}{c}\mathrm{eGFR} \\
\mathrm{mL} / \mathrm{min} / 1.73 \mathrm{~m}^{2}\end{array}$ \\
\hline 36 & 142 & 4.7 & 109 & $\mathrm{ND}$ & 24 & 7.36 & 2.9 & 27 \\
\hline 37 & 142 & 3.9 & 103 & ND & 30 & 7.31 & 3.4 & 21 \\
\hline 38 & 143 & 3.9 & 105 & 2 & 29 & 7.41 & 3.9 & 18 \\
\hline 39 & 138 & 4.3 & 104 & 2 & 31 & 7.35 & 4.2 & 16 \\
\hline 40 & 144 & 4.2 & 110 & 1.8 & 24 & 7.31 & 4.3 & 16 \\
\hline 42 & 143 & 4.1 & 106 & 1.6 & 27 & 7.33 & 5.4 & 12 \\
\hline
\end{tabular}

$\mathrm{Na}$, sodium; $\mathrm{K}$; potassium, $\mathrm{Cl}$, chloride; $\mathrm{Mg}$, magnesium; $\mathrm{HCO}_{3}{ }^{-}$, bicarbonate ion; eGFR, estimated glomerular filtration rate; $\mathrm{ND}$, not determined.

\subsection{Follow-Up Study}

Since genetic studies showed a likely pathogenic missense mutation in PKD1 in heterozygosis, we classified the patient as PROPKD 4 score (low risk of progression) [36] and Mayo class 1B (low risk of progression). However, his TKV and htTKV values were significantly smaller than two of our PKD1 cohorts used to monitor our proband (PKD1 patients $\leq 40$ years, and PKD1 with BMI $<25)$, but not smaller than PKD1 without hypertension (Table 2). In fact, eGFR in the proband was significantly lower than the three PKD1 cohorts, according with his prediction of future eGFR (ESRD at 48 years, high risk of progression). Moreover, Table 1 shows that the patient experimented a rapid progression from CRF to ESRD in only four years.

Interestingly, the proband had no clinical features related to GS, at all. He showed that the serum magnesium (1.6-2.0 mg/dL) and potassium levels (3.9-4.7 mmol/L), and venous ( $\mathrm{pH}$ 7.31-7.41) were within normal limits, although HCO3- levels in blood were inappropriately higher $(24-31 \mathrm{mmol} / \mathrm{L})$ for his grade of CRF (Table 1). It is remarkable that during the follow-up course his blood pressure remained normal to low, despite the presence of severe CRF, including ESRD; he also had an intolerance to telmisartan treatment. 
Table 2. Clinical features of the proband when compared with three different PKD1 cohorts in our Centre.

\begin{tabular}{|c|c|c|c|c|}
\hline Parameter & Proband & $\begin{array}{c}\text { PKD1's Patients } \\
\text { without HT } \\
(n=23, \text { Mean } \pm \text { SD })\end{array}$ & $\begin{array}{c}\text { PKD1's Patients } \\
\leq 40 \text { Year-Old } \\
(n=58, \text { Mean } \pm \text { SD })\end{array}$ & $\begin{array}{c}\text { PKD1's Patients with } \\
\text { BMI < } 25 \\
(n=54, \text { Mean } \pm \text { SD })\end{array}$ \\
\hline Age, years & 36 & $35.0 \pm 5.6$ & $33.1 \pm 6.3$ & $38.1 \pm 10.0$ \\
\hline $\mathrm{TKV}, \mathrm{mL}$ & 726 & $662.0 \pm 223.0$ & $1301.0 \pm 966.0$ & $1264.0 \pm 750.0$ \\
\hline $\mathrm{HtTKV}, \mathrm{mL} / \mathrm{m}$ & 370 & $382.0 \pm 124.0$ & $752.0 \pm 563.0$ & $746.0 \pm 449.0$ \\
\hline $\mathrm{eGFR}, \mathrm{mL} / \mathrm{min} / 1.73 \mathrm{~m}^{2}$ & 27 & $137.0 \pm 19.0$ & $119.0 \pm 30.0$ & $117.0 \pm 30.0$ \\
\hline
\end{tabular}

TKV, total kidney volume; htTKV, height adjusted total kidney volume; HT, hypertension; BMI, body mass index eGFR; estimated glomerular filtration rate; SD, standard deviation.

3.3. Genetic Analysis. Coexistence of PKD1 and SLC12A3 Variants, and 47, XXY Karyotype in Our Proband

\subsubsection{Fertility Studies}

Cytogenetic analysis of peripheral blood showed a 47, XY,+X karyotype (Figure 1D). $\mathrm{Y}$-chromosome microdeletion analysis and variant analysis of the CFTR gene were negative.

\subsubsection{NGS Studies}

NGS studies detected a previously described missense variant in PKD1; NM_001009944.3:c.9499A>T(p.Ile3167Phe) (Figure 1E, left) in heterozygosis at exon 27. This variant was reported in different ethnicities [12,37-39], including European NonFinnish (although in the latter ones, with a population frequency under the threshold established for nonpathogenic variants; source, Varsome). It was previously classified as a variant of uncertain significance VUS (http://pkdb.mayo.edu/ (accessed on 14 December 2021); ADPKD mutation database), and as a disease (Uniprot), which reflect conflicting interpretations of pathogenicity (ClinVar), as well as VUS (LOVD), VUS (HGMD), and, following ACMG/AMP ${ }^{2}$ criteria [40], it is likely pathogenic (LP) (PM1, PP2, PP3, PP4, PP5, BS2). In addition, we detected a second PKD1 missense variant NM_001009944.3:c.9756G>C(p.Glu3252Asp) (Figure 1E, right) in heterozygosis at exon 29, that was not previously reported in known databases (Mayo, Uniprot, ClinVar, LOVD, ALAMUT), nor in gnomAD research projects. It was classified using ACM/AMP ${ }^{2}$ criteria as VUS (PM2, PP2, PP3). Both variants were validated by Sanger sequencing in the proband. In addition, NGS analysis also established two SLC12A3 variants, NM_000339.3:c.1928C > T (p.Pro643Leu) (Figure 1F, left) in exon 16 and NM_000339.3:c.2891G>A(p.Arg964Gln) (Figure 1F, right) in exon 25, associated with GS. Both SNVs were previously described in clinical databases (p.Pro643Leu: ClinVar; conflicting interpretation of pathogenicity; LOVD, LP; Uniprot, disease; Varsome, LP/pathogenic (P) and p.Arg964Gln: ClinVar; LP/P; LOVD, P; Varsome, LP, P) and classified under ACMG/AMP 2 criteria as LP and P, respectively. Both variants were also confirmed by Sanger sequencing only in the proband (no other members of the family were available at this time). Thus, we cannot establish familial segregation for those and previous variants. No other pathogenic variants were found in other ADPKD-associated genes ( $P K D H 1, G A N A B, A C E$, etc,) or related to cyst progression. The analysis of CNV by means of MLPA for PKD1, and PKD2, and the rest of the panel (using the algorithm Lacon v1.2 tool; INGEMM) was negative. Genetic findings are shown in Table 3. 
Table 3. Summary of the genetic findings that may be associated with clinical features on the proband.

\begin{tabular}{|c|c|c|c|c|c|c|}
\hline Gene & Genomic Findings & Variant Type & Chromosome & Disease & Inheritance & $\begin{array}{c}\text { Clinical } \\
\text { Significance }\end{array}$ \\
\hline PKD1 & $\begin{array}{c}\text { c.9499A > T } \\
\text { (p.Ile3167Phe) }\end{array}$ & Missense & $16 \mathrm{p} 13.3$ & ADPKD & $\mathrm{AD}$ & $\begin{array}{c}\text { Likely } \\
\text { pathogenic }\end{array}$ \\
\hline PKD1 & $\begin{array}{c}\text { c.9756G>C } \\
\text { (p.Glu3252Asp) }\end{array}$ & Missense & $16 \mathrm{p} 13.3$ & ADPKD & $\mathrm{AD}$ & $\begin{array}{l}\text { Uncertain } \\
\text { significance }\end{array}$ \\
\hline SLC12A3 & $\begin{array}{c}\text { c.1928C }>\text { T } \\
\text { (p.Pro643Leu) } \\
\text { c.2891G>A } \\
\text { (p.Arg964Gln) }\end{array}$ & $\begin{array}{l}\text { Missense } \\
\text { Missense }\end{array}$ & $16 \mathrm{q} 13$ & $\begin{array}{l}\text { Gitelman } \\
\text { syndrome }\end{array}$ & $\mathrm{AR}$ & $\begin{array}{l}\text { Pathogenic } \\
\text { Pathogenic }\end{array}$ \\
\hline X-chromosome & 47, XY,+X karyotype & Aneuploidy & $x$ & $\begin{array}{l}\text { Klinefelter } \\
\text { syndrome }\end{array}$ & - & Pathogenic \\
\hline
\end{tabular}

\section{Discussion}

\section{1. $A D P K D$}

In ADPKD, the uncontrolled growth of renal cysts increases renal volume and the destruction of the parenchyma progressively, resulting in renal failure in most patients [41]. In addition, endothelial dysfunction which occurs very early in the course of the disease appears to be involved in increased oxidative stress and inflammation [42,43]. Then, the progression of ADPKD is highly variable, in part because of the gene affected [1-7], as well as the presence of other variants modifying its effect. In fact, how environmental factors and/or modifier genes/variants may modulate ADPKD, involving a rapid progression of the disease $[6-8,13,44,45]$, is still unknown. Indeed, the presence of additional gene variants may promote cystogenesis and/or fibrosis, and potentiate the advancement toward ESRD [4-8,14]. At this point, there is some evidence of how synergistic effects between PKD1 and PKD2 loci may accelerate the progression to ESRD approximately 20 years earlier than patients with only $P K D 1$ sequence variants $[6,7]$.

Cyst growth in ADPKD is associated with increases in epithelial cell proliferation, dedifferentiation, and fluid secretion. Then, the enlargement of cysts affects surrounding nephrons interrupts kidney function significantly [36,41,44]. Indeed, cyst pressure induces renin-angiotensin-aldosterone system (RAAS) activation and kidney hypoxia. At the late stage of ADPKD, cyst formation is always accompanied by extracellular matrix deposition and fibrosis formation [14,15,41], which reduces renal function and eventually leads to progression to ESRD [14,41]. In addition, oxidative stress/reactive oxygen species (ROS) in ADPKD has also been considered a new player and/or early predictor for such disease progression [46,47], either directly, starting endothelial dysfunction and generating arterial atherosclerosis, or weakening of the arterial medial layer leading to arterial aneurysms [48]. Therefore, ADPKD can also be related to extra-renal manifestations, such as symptomatic extra-renal cysts, hypertension, and subarachnoid hemorrhage from intracranial aneurysms $[49,50]$.

Interestingly, we classified our proband as low risk of progression (Mayo class $1 \mathrm{~B}$ and PROPKD 4 score), however, the eGFR predicted established the development of ESRD at 48 years (rapid progression). In fact, his real situation of ESRD had been achieved at age of 40 (eGFR $16 \mathrm{~mL} / \mathrm{min} / 1.73 \mathrm{~m}^{2}$ ) or 42 years (eGFR $12 \mathrm{~mL} / \mathrm{min} / 1.73 \mathrm{~m}^{2}$ ). Furthermore, his eGFR was significantly lower than expected when it was compared with three different age-matched ADPKD cohorts, one with similar htTKV (Table 2). Thus, we suggest the predominant expression of renal tubulointerstitial inflammation, apoptosis, fibrosis, and/or vascular disease over cyst growth in this patient. It may explain the discordance observed between different markers of risk of ADPKD progression and between htTKV and eGFR evolution. 


\subsection{Klinefelter Syndrome}

The presence of more than one X-chromosome in men characterized KS, which is the most common genetic cause of human male infertility. KS is related to high comorbidity with a lower life expectancy. It is thought that overexpression of some genes on the extra $\mathrm{X}$-chromosome may be the cause. However, what genes and how they interact remain unclear [51-54]. We know that KS individuals may have an increased risk of cardiovascular and cerebrovascular diseases [18], an aspect that could affect the severity of the extra-renal complications in our patient. Due to the Lyonization phenomenon, in KS individuals only one of the X-chromosomes in the somatic cells is fully active, although around $15 \%$ of the genes on the inactive $\mathrm{X}$-chromosome continue to be expressed, albeit at a lower level. Thus, recent works, focused on identifying those gene clusters that escape from $\mathrm{X}$-inactivation in KS patients, have revealed altered functionality in KS by several protein complexes grouped by clusters [53]. Among those clusters, one of the most significant comorbidity clusters includes PKD1 [53]. In addition, KS can lead to structural alterations in tissues [16] in different ways, including heart diseases, insulin resistance [18], thrombotic events, or subarachnoid hemorrhage from an intracranial saccular aneurysm rupture $[20,21,55]$. These facts could affect the process of mitochondrial oxidative phosphorylation (OXPHOS) [24] The association of KS with other disorders is expected due to the relatively high frequency of this entity [56].

\subsection{Hypergonadotropic Hypogonadism}

Male ADPKD patients may present with several reproductive system abnormalities and infertility [57-59]. Patients with KS usually show gonadal dysfunction with increased FSH and LH levels. Similar hormonal dysfunction was often found in male patients with CRF of any etiology [60]. So, CRF is associated with an increase in the FSH and the LH levels due to the impairment of the renal function in catabolizing these hormones, with normalization after renal transplantation [60]. Consequently, if a patient has these two conditions (KS and CRF from ADPKD) at the same time, the presence of an increase in the FSH and the LH levels, which are seen in CRF, can overlap with the KS manifestations masking and leaving the KS undiagnosed. This case illustrates an under-recognized lag in the diagnosis of hypergonadotropic hypogonadism, since the superposition of the two events is rare (decrease in free testosterone and increase in FSH and LH levels), indicating that in addition to KS, this effect may be caused by coexisting CRF.

\subsection{Gitelman Syndrome}

GS caused by SLC12A3 sequence variations is characterized by hypochloremic metabolic alkalosis, hypomagnesemia, RAAS activation with normal or low blood pressure, salt loss, and hypokalemia [27]. Identification of biallelic pathogenic variants in SLC12A3 is necessary for establishing the diagnosis of GS. NGS showed two previously reported heterozygous missense variants in the SLC12A3 gene: c.1928C >T(p.Pro643Leu) and c.2891G >A(p.Arg964Gln). However, we have not found electrolyte alterations characteristic of GS in our proband. Thus, the phenotypic effect of such missense variants is difficult to evaluate, and some pathogenic variants may not be sufficient to cause phenotypic changes related to GS [27-31], although, we cannot rule out that modifier genes are involved in the onset of GS or that phenotypic changes caused by this compound heterozygous would be apparent later in life. Indeed, our proband had a reduced eGFR at the time of the first evaluation, and this fact could in part mask the electrolyte alterations of GS (Table 1).

\subsection{Co-Occurrence of $A D P K D, K S$, and GS}

We describe the first report of ADPKD combined with KS and GS, which initially were unnoticed, indicating the need to consider the concurrent existence of additional disorders in cases of atypical ADPKD manifestations. This patient carries clinically significant variants in two different genes and a huge genomic rearrangement (one extra X-chromosome) responsible for additional pathology. Therefore, all these entities in one individual are not 
common, but it depends on the prevalence of each disease. Taking into account that their prevalences are around one in 500-1000 (ADPKD) [3,4] and one in 500-1000 (KS) male births $[16,17]$, respectively, the probability for the simultaneous occurrence of these two disorders is approximately 1/250,000-1,000,000 births. Therefore, the occurrence of both ADPKD and KS in a single individual is in fact, theoretically, very rare. The prevalence of GS is estimated at approximately 1:40,000 [27]. Then, the occurrence of ADPKD, KS, and GS is even a rarer event. The effects of two or more genetic disorders in the same patient are unknown, and they can be additives, protectives, or neutrals [61], and may be influenced by the extent to which the clinical features with each individual disease overlaps with the other. Thus, the diseases can be distinct or overlapping. Distinct effects may affect different organ systems, whereas overlapping clinical effects are more likely to be caused by two genes encoding for proteins that normally interact within the same signaling pathway. Since ADPKD in association with KS and GS has never been reported in the literature, the possible effect of each other is currently unknown. Therefore, at this point, it is not clear if KS and GS will affect the cyst progression of ADPKD or vice versa. Indeed, the severe ADPKD phenotype denoted in our patient can be a consequence of two, not so strong variants in PKD1 gene associated with other genetic variants (two SLC12A3 variants and an extra X-chromosome). In addition, we cannot rule out that the PKD1 variant c.9756G>C may have a role as a hypomorphic allele [11,12], or may occur from a putative alteration of topological chromatin organization (TAD; topologically associating domains). We now know that enhancers regulate the expression of distal target genes via long-range regulatory chromatin loops within the genomic context of TADs [62]. The later hypothesis needs to be also explored.

The clinical progression to ESRD and disease prognosis in this patient with ADPKD, KS, and GS (isolated KS or GS not producing CRF) could be potentially synergistic and comparable to individuals with variants in both PKD1 and PKD2 [6,7], hypomorphic PKD1 variants and likely biallelic disease [12], the contiguous gene syndrome TSC2-PKD1 [8], co-occurrence of ADPKD and hereditary renal hypouricemia [45], or dual sequence variants in PKD2 and COL4A1 [63]. In fact, our patient with an LP variant in PKD1, KS, and a compound heterozygous GS-associated variant showed a severe phenotype of ADPKD, characterized by the development of early CRF (at 27 years old) and rapid evolution to ESRD (at 40 years old) (Table 1), associated with an intracranial aneurysm (Figure 1C). He developed ESRD 15-20 years earlier than patients with a P/LP variant in PKD1 (average age of 58 years) $[4,24,37,38]$. Indeed, our patient also carries features that are atypical for ADPKD, such as the development of early CRF without severe hypertension and quick evolution to ESRD, typically associated with significant cyst burden. However, he only manifested moderate ADPKD by kidney length. This fact suggests a putative effect of modifier genes with a predominant development of fibrosis over cyst growth, as has been demonstrated in a TGF- $\beta 1$-induced fibrosis murine model $[64,65]$. Therefore, discordance between cyst burden and renal function decline trajectories that could be explained by lower cyst growth and remarkably slowed kidney enlargement in this ADPKD patient. In the present study, it was hypothesized that coexisting ADPKD with masked KS and GS may have a synergistic effect on the stimulation of rapid evolution to ESRD, and their synergistic effect may be the result of regulation of multiple signaling pathways, including vascular disease [66-73] (see Figure 2).

On the other hand, in both ADPKD and KS there is an elevated frequency of intracranial aneurysms and, in the case of associated variants in PKD1 protein and KS, it is expected to have at least additive intracranial aneurysms in disease presentation $[21,49,50,55]$. Thus, inferred by our data, he appears to be more severely affected than is typically reported with either condition alone. In fact, we detected an intracranial aneurysm with increased growth in a short period of time. Thus, the presence of an additive/synergistic effect may be explained by the underlying molecular function of the polycystin-1 protein and KS. Indeed, it has been previously established that loss of polycystin- 1 function reduces control of Ras and aberrant activation of the mTOR pathway. Moreover, activation of the 
mTOR pathway and increased vascular endothelial apoptosis in KS [66] and ADPKD could affect the intracranial aneurysm growth in our patient $[23,24,67]$. Finally, other possible factors that could affect ADPKD progression and the growth of the intracranial aneurysm in this patient include also an increased RAAS stimulation, apoptosis, fibrosis, and vascular disease $[26,27,68]$.

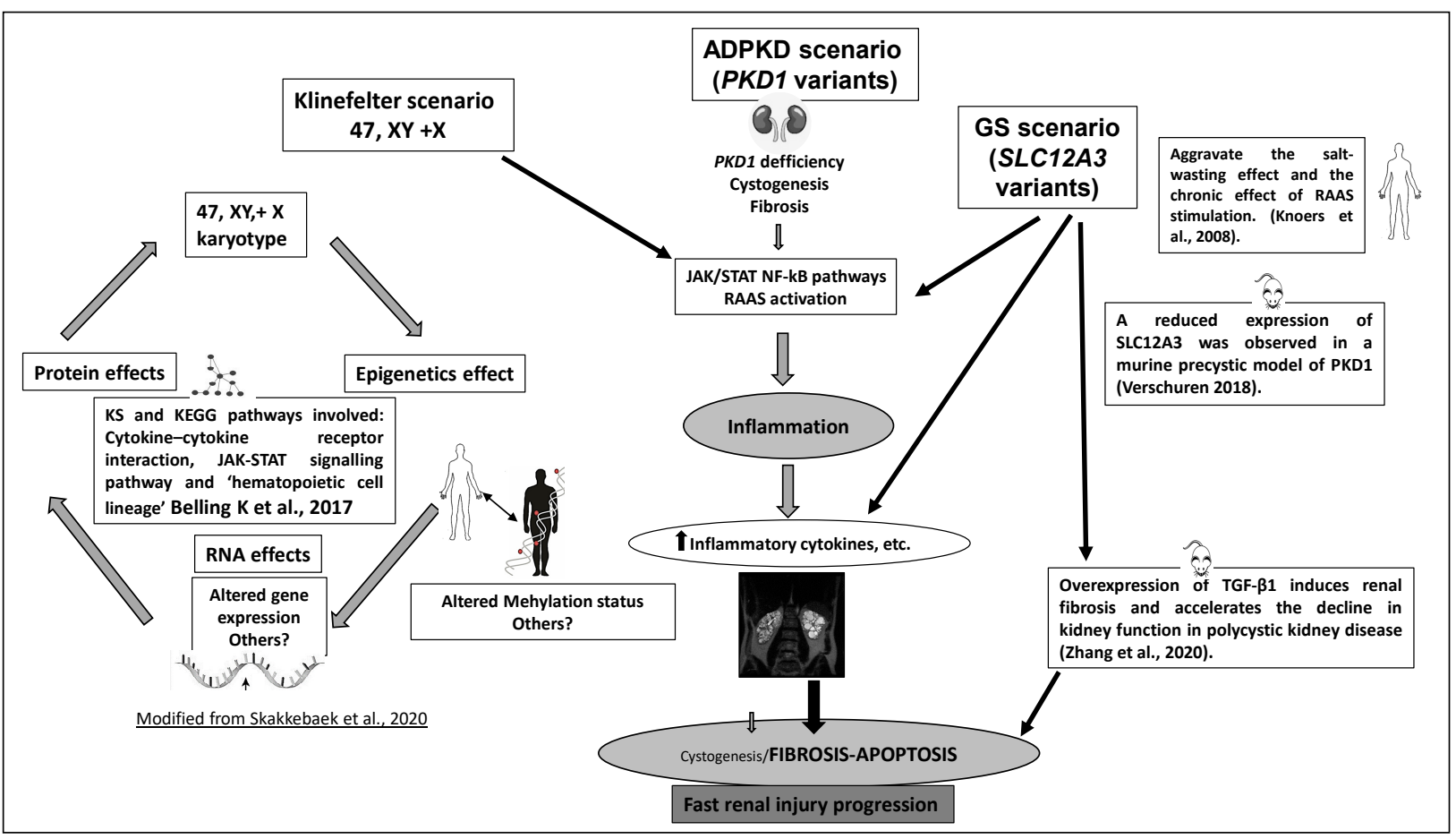

Figure 2. Hypothetical scheme for putative mechanisms on synergistic ADPKD pathogenesis and additional effects of KS and GS in our proband. Based in animal and human models of disease.

\section{Conclusions}

We present, for the first time a young ADPKD patient with an early, fast progression to ESRD, as well as growth of an intracranial aneurysm, accompanied with masqueraded KS and GS. We think that the presence of a 47, XXY karyotype and compound heterozygous variants in SLC12A3 may increase the pathogenic action of PKD1 variants. This is done, we presume, by increasing apoptosis, fibrosis, and producing predominant tubule-interstitial and vascular renal injury, instead of cystic growth, as it has been suggested in murine models. The use of NGS in the genetic diagnosis of different diseases is currently demonstrating the coexistence of several genetic variants in the same patient, which may contribute to the high variability and heterogeneity observed in numerous individuals. This case illustrates the importance of performing genetic testing to establish a complete diagnosis in ADPKD patients with atypical presentations and/or with fertility abnormalities.

Author Contributions: The complete list of authors approved this manuscript. R.P. and J.N. have made substantial in all aspects of the manuscript, including writing the article. F.A.G.-S. made cytogenetic studies. E.C. made and interpreted image studies. M.O. and S.A. made clinical data updates of the patient. R.M., C.P., E.C. and P.L. established significant discussion about the data and figures, as well as a critical reading of the manuscript. All authors have read and agreed to the published version of the manuscript.

Funding: This study was financed in part by Instituto de Salud Carlos III (Ministerio de Ciencia e Innovación; EC08/00236) and by Programa de Intensificación en Investigación científica del IdiPAZ to Peces and Nevado. 
Institutional Review Board Statement: The study was conducted in accordance with the Declaration of Helsinki, and approved by the Institutional Review Board (or Ethics Committee) of Hospital Universitario La Paz (PI279).

Informed Consent Statement: Informed consent was obtained from the subject involved in the study.

Data Availability Statement: The URLs for data presented herein are as follows: Exome Aggregation Consortium Browser, http:/ / exac.broadinstitute.org/, accessed on 7 December 2021; The Genome Aggregation Database (gnomAD), https: / / gnomad.broadinstitute.org/, accessed on 7 December 2021; Human Genetic Variation Database, Exome Sequencing Project, http:/ / evs.gs.washington.edu/EVS/, accessed on 7 December 2021; dbSNP Short Genetic Variations, http:/ / www.ncbi.nlm.nih.gov/SNP/, accessed on 7 December 2021; The Genome Analysis Toolkit (GATK), https: / / www.broadinstitute. org/gatk/, accessed on 7 December 2021; Picard, http:/ / broadinstitute.github.io/picard/, accessed on 7 December 2021; Annovar, http:/ / annovar.openbioinformatics.org/en/latest/, accessed on 7 December 2021; Polyphen2, http:/ / genetics.bwh.harvard.edu/pph2/, accessed on 7 December 2021; SIFT, http:/ / sift.jcvi.org/, accessed on 7 December 2021; MutationTaster, http:/ / www.mutationtaster. org/, accessed on 7 December 2021; RefSeq, http:/ / www.ncbi.nlm.nih.gov/refseq/, accessed on 7 December 2021; UCSC Human Genome Browser, https:/ / genome.ucsc.edu/, accessed on 7 December 2021; OMIM, http:/ / www.omim.org/, accessed on 7 December 2021; ClinVar database, https: / / www.ncbi.nlm.nih.gov/clinvar, accessed on 7 December 2021; Beacon. https:/ / beacon-network.org/ \#/1000/, accessed on 7 December 2021; Genomes Project. https:/ / www.internationalgenome.org/ category/phase-3kaviar, accessed on 7 December 2021; HGMD. http:/ / www.hgmd.cf.ac.uk/ac/ index.php, accessed on 7 December 2021; LOVD. https:/ / www.lovd.nl/ Alamut ${ }^{\circledR}$, accessed on 7 December 2021. https:/ / www.interactive-biosoftware.com/alamut-visuai, accessed on 7 December 2021; Varsome. https://varsome.com/, accessed on 7 December 2021; ENCODE Project. https: //www.encodeproject.org/, accessed on 7 December 2021.

Acknowledgments: The authors thank the affected individual and his family who contributed to this study.

Conflicts of Interest: The authors declare no conflict of interest.

\section{References}

1. Gall, E.C.-L.; Audrézet, M.-P.; Chen, J.-M.; Hourmant, M.; Morin, M.-P.; Perrichot, R.; Charasse, C.; Whebe, B.; Renaudineau, E.; Jousset, P.; et al. Type of PKD1 mutation influences renal outcome in ADPKD. J. Am. Soc. Nephrol. 2013, 24, 1006-1013. [CrossRef]

2. Cornec-Le Gall, E.; Torres, V.E.; Harris, P.C. Genetic complexity of autosomal dominant polycystic kidney and liver diseases. J. Am. Soc. Nephrol. 2018, 29, 13-23. [CrossRef]

3. Bergmann, C.; Guay-Woodford, L.M.; Harris, P.C.; Horie, S.; Peters, D.J.M.; Torres, V.E. Polycystic kidney disease. Nat. Rev. Dis. Primers 2018, 4, 50. [CrossRef]

4. Torres, V.E.; Harris, P.C.; Pirson, Y. Autosomal dominant polycystic kidney disease. Lancet 2007, 369, 1287-1301. [CrossRef]

5. Rossetti, S.; Burton, S.; Strmecki, L.; Pond, G.R.; Millán, J.L.S.; Zerres, K.; Barratt, T.M.; Ozen, S.; Torres, V.E.; Bergstralh, E.J.; et al. The position of the polycystic kidney disease 1 (PKD1) gene mutation correlates with the severity of renal disease. J. Am. Soc. Nephrol. 2002, 13, 1230-1237. [CrossRef]

6. $\quad$ Audrézet, M.-P.; Corbiere, C.; Lebbah, S.; Morinière, V.; Broux, F.; Louillet, F.; Fischbach, M.; Zaloszyc, A.; Cloarec, S.; Merieau, E.; et al. Comprehensive PKD1 and PKD2 mutation analysis in prenatal autosomal dominant polycystic kidney disease. J. Am. Soc. Nephrol. 2016, 27, 722-729. [CrossRef]

7. Bergmann, C.; von Bothmer, J.; Ortiz Brüchle, N.; Venghaus, A.; Frank, V.; Fehrenbach, H.; Hampel, P.; Pape, L.; Buske, A.; Jonsson, J.; et al. Mutations in multiple PKD genes may explain early and severe polycystic kidney disease. J. Am. Soc. Nephrol. 2011, 22, 2047-2056. [CrossRef]

8. Consugar, M.B.; Wong, W.C.; Lundquist, P.A.; Rossetti, S.; Kubly, V.J.; Walker, D.L.; Rangel, L.J.; Aspinwall, R.; Niaudet, W.P.; Özen, S.; et al. Characterization of large rearrangements in autosomal dominant polycystic kidney disease and the PKD1/TSC2 contiguous gene syndrome. Kidney Int. 2008, 74, 1468-1479. [CrossRef]

9. Pei, Y. A "two-hit" model of cystogenesis in autosomal dominant polycystic kidney disease. Trends Mol. Med. 2001, 7, 151-156. [CrossRef]

10. Wu, G.; Tian, X.; Nishimura, S.; Markowitz, G.S.; D’Agati, V.; Park, J.H.; Yao, L.; Li, L.I.; Geng, L.; Zhao, H.; et al. Transheterozygous Pkd1 and Pkd2 mutations modify expression of polycystic kidney disease. Hum. Mol. Genet. 2002, 11, 1845-1854. [CrossRef]

11. Reiterova, J.; Stekrova, J.; Merta, M.; Kotlas, J.; Elišáková, V.; Lněnička, P.; Korabečná, M.; Kohoutova, M.; Tesař, V. Autosomal dominant polycystic kidney disease in a family with mosaicism and hypomorphic allele. BMC Nephrol. 2013, 1459, 20. [CrossRef] 
12. Durkie, M.; Chong, J.; Valluru, M.K.; Harris, P.C.; Ong, A.C.M. Biallelic inheritance of hypomorphic PKD1 variants is highly prevalent in very early onset polycystic kidney disease. Genet. Med. 2021, 23, 689-697. [CrossRef]

13. Harris, P.C.; Torres, V.E. Genetic mechanisms and signaling pathways in autosomal dominant polycystic kidney disease. J. Clin. Investig. 2014, 124, 2315-2324. [CrossRef]

14. Norman, J. Fibrosis and progression of autosomal dominant polycystic kidney disease (ADPKD). Biochim. Biophys. Acta 2011, 1812, 1327-1336. [CrossRef]

15. Xue, C.; Mei, C.L. Polycystic kidney disease and renal fibrosis. Adv. Exp. Med. Biol. 2019, 1165, 81-100.

16. Los, E.; Ford, G.A. Klinefelter Syndrome. [Updated 2019 Dec 2]. In StatPearls; StatPearls Publishing: Treasure Island, FL, USA, 2020. Available online: https:/ / www.ncbi.nlm.nih.gov/books/NBK482314/?log $\$=$ activity (accessed on 7 December 2021).

17. Bojesen, A.; Juul, S.; Gravholt, C.H. Prenatal and postnatal prevalence of Klinefelter syndrome: A national registry study. J. Clin. Endocrinol. Metab. 2003, 88, 622-626. [CrossRef]

18. Calogero, A.E.; On behalf of the Klinefelter ItaliaN Group (KING); Giagulli, V.A.; Mongioì, L.M.; Triggiani, V.; Radicioni, A.F.; Jannini, E.A.; Pasquali, D. Klinefelter Italian group (KING). Klinefelter syndrome: Cardiovascular abnormalities and metabolic disorders. J. Endocrinol. Investig. 2017, 40, 705-712. [CrossRef]

19. Pasquali, D.; Arcopinto, M.; Renzullo, A.; Rotondi, M.; Accardo, G.; Salzano, A.; Esposito, D.; Saldamarco, L.; Isidori, A.; Marra, A.M.; et al. Cardiovascular abnormalities in Klinefelter syndrome. Int. J. Cardiol. 2013, 168, 754-759. [CrossRef]

20. Kominato, Y.; Fujikura, T.; Matsui, K.; Hata, N.; Takizawa, H. Acute cerebellar hemorrhage in a patient with Klinefelter syndrome: XXY karyotype obtained postmortem from cells from pericardial fuid. J. Forensic. Sci. 2000, 45, 1148-1150. [CrossRef]

21. Salzano, A.; Arcopinto, M.; Marra, A.M.; Bobbio, E.; Esposito, D.; Accardo, G.; Giallauria, F.; Bossone, E.; Vigorito, C.; Lenzi, A.; et al. Management of endocrine disease: Klinefelter syndrome, cardiovascular system, and thromboembolic disease: Review of literature and clinical perspectives. Eur. J. Endocrinol. 2016, 175, R27-R40. [CrossRef]

22. Swerdlow, A.J.; Schoemaker, M.J.; Higgins, C.D.; Wright, A.F.; Jacobs, P.A. Cancer incidence and mortality in men with Klinefelter syndrome: A cohort study. J. Natl. Cancer Inst. 2005, 97, 1204-1210. [CrossRef]

23. Cimino, L.; Salemi, M.; Cannarella, R.; Condorelli, R.A.; Giurato, G.; Marchese, G.; La Vignera, S.; Calogero, A.E. Decreased miRNA expression in Klinefelter syndrome. Sci. Rep. 2017, 7, 16672. [CrossRef]

24. Salemi, M.; Cannarella, R.; Condorelli, R.A.; Cimino, L.; Ridolfo, F.; Giurato, G.; Romano, C.; Vignera, S.L.; Calogero, A.E. Evidence for long noncoding RNA GAS5 up-regulation in patients with Klinefelter syndrome. BMC Med. Genet. $2019,2,4$.

25. Dulovic, M.; Schäffer, E.; Leypoldt, F.; Balck, A.; Schaake, S.; Hinrichs, F.; Kirchner, H.; Brüggemann, N.; Berg, D.; Lohmann, K. A Klinefelter patient with an additional mitochondrial mutation: Implications for genotype-driven treatment and mitochondrial mutational load in different tissues and family members. Parkinsonism Relat. Disord. 2018, 54, 116-118. [CrossRef]

26. Condorelli, R.A.; Calogero, A.E.; La Vignera, S. Different profile of endothelial cell apoptosis in patients with Klinefelter's syndrome. J. Endocrinol. Investig. 2013, 36, 84-91.

27. Knoers, N.V.; Levtchenko, E.N. Gitelman syndrome. Orphanet J. Rare Dis. 2008, 3, 22. [CrossRef]

28. Fujimura, J.; Nozu, K.; Yamamura, T.; Minamikawa, S.; Nakanishi, K.; Horinouchi, T.; Nagano, C.; Sakakibara, N.; Nakanishi, K.; Shima, Y.; et al. Clinical and genetic characteristics in patients with Gitelman syndrome. Kidney Int. Rep. 2019, 4, 119-125. [CrossRef]

29. Ishikawa, M.; Tada, Y.; Tanaka, H.; Morii, W.; Inaba, M.; Takada, H.; Mori, T.; Noguchi, E. A family with Gitelman syndrome with asymptomatic phenotypes while carrying reported SLC12A3 mutations. Case Rep. Nephrol. Dial. 2020, 10, 71-78. [CrossRef]

30. Shen, Q.; Chen, J.; Yu, M.; Lin, Z.; Nan, X.; Dong, B.; Fang, X.; Chen, J.; Ding, G.; Zhang, A.; et al. Multi-centre study of the clinical features and gene variant spectrum of Gitelman syndrome in Chinese children. Clin. Genet. 2021, 99, 558-564. [CrossRef]

31. Chen, Q.; Wang, X.; Min, J.; Wang, L.; Mou, L. Kidney stones and moderate proteinuria as the rare manifestations of Gitelman syndrome. BMC Nephrol. 2021, 22, 12. [CrossRef]

32. Bae, K.T.; Commean, P.K.; Lee, J. Volumetric measurement of renal cysts and parenchyma using MRI: Phantoms and patients with polycystic kidney disease. J. Comput. Assist. Tomogr. 2000, 24, 614-619. [CrossRef] [PubMed]

33. Irazabal, M.V.; Rangel, L.J.; Bergstralh, E.J.; Osborn, S.L.; Harmon, A.J.; Sundsbak, J.L.; Bae, K.T.; Chapman, A.B.; Grantham, J.J.; Mrug, M.; et al. Imaging classification of autosomal dominant polycystic kidney disease: A simple model for selecting patients for clinical trials. J. Am. Soc. Nephrol. 2015, 26, 160-172. [CrossRef] [PubMed]

34. Harris, P.C. The time for next-generation molecular genetic diagnostics in nephrology is now! Kidney Int. 2018, 94, 237-239. [CrossRef] [PubMed]

35. Krausz, C.; Hoefsloot, L.; Simoni, M.; Tüttelmann, F. European Academy of Andrology; European Molecular Genetics Quality Network. EAA/EMQN best practice guidelines for molecular diagnosis of Y-chromosomal microdeletions: State-of-the-art 2013. Andrology 2014, 2, 5-19. [CrossRef] [PubMed]

36. Lavu, S.; Vaughan, L.E.; Senum, S.R.; Kline, T.L.; Chapman, A.B.; Perrone, R.D.; Mrug, M.; Braun, W.E.; Steinman, T.I.; RahbariOskoui, F.F.; et al. The value of genotypic and imaging information to predict functional and structural outcomes in ADPKD. JCI Insight 2020, 5, e138724. [CrossRef]

37. Rossetti, S.; Chauveau, D.; Walker, D.; Saggar-Malik, A.; Winearls, C.G.; Torres, V.E.; Harris, P.C. A complete mutation screen of the ADPKD genes by DHPLC. Kidney Int. 2002, 61, 1588-1599. [CrossRef] 
38. Solazzo, A.; Testa, F.; Giovanella, S.; Busutti, M.; Furci, L.; Carrera, P.; Ferrari, M.; Ligabue, G.; Mori, G.; Leonelli, M.; et al. The prevalence of autosomal dominant polycystic kidney disease (ADPKD): A meta-analysis of European literature and prevalence evaluation in the Italian province of Modena suggest that ADPKD is a rare and underdiagnosed condition. PLoS ONE 2018, 13, e0190430. [CrossRef]

39. Mantovani, V.; Bin, S.; Graziano, C.; Capelli, I.; Minardi, R.; Aiello, V.; Ambrosini, E.; Cristalli, C.P.; Mattiaccio, A.; Pariali, M.; et al. Gene panel analysis in a large cohort of patients with autosomal dominant polycystic kidney disease allows the identification of 80 potentially causative novel variants and the characterization of a complex genetic architecture in a subset of families. Front. Genet. 2020, 11, 464. [CrossRef]

40. Richards, S.; Aziz, N.; Bale, S.; Bick, D.; Das, S.; Gastier-Foster, J.; Grody, W.W.; Hegde, M.; Lyon, E.; Spector, E.; et al. Standards and guidelines for the interpretation of sequence variants: A joint consensus recommendation of the American College of Medical Genetics and Genomics and the Association for Molecular Pathology. Genet. Med. 2015, 17, 405-424. [CrossRef]

41. Grantham, J.J.; Mulamalla, S.; Swenson-Fields, K.I. Why kidneys fail in autosomal dominant polycystic kidney disease. Nat. Rev. Nephrol 2011, 7, 556-566. [CrossRef]

42. Bellos, I.; Kontzoglou, K.; Perrea, D.N. Markers of endothelial dysfunction and arterial stiffness in patients with early-stage autosomal dominant polycystic kidney disease: A meta-analysis. Int. J. Clin. Pract. 2020, 18, e13721. [CrossRef] [PubMed]

43. Formica, C.; Peters, D.J.M. Molecular pathways involved in injury-repair and ADPKD progression. Cell Signal. 2020, 72, 109648. [CrossRef] [PubMed]

44. Xue, C.; Zhou, C.; Mei, C. Total kidney volume: The most valuable predictor of autosomal dominant polycystic kidney disease progression. Kidney Int. 2018, 93, 540-542. [CrossRef] [PubMed]

45. Peces, R.; Mena, R.; Peces, C.; Cuesta, E.; Selgas, R.; Barruz, P.; Lapunzina, P.; Nevado, J. Coexistence of autosomal dominant polycystic kidney disease type 1 and hereditary renal hypouricemia type 2: A model of early-onset and fast cyst progression. Clin. Genet. 2020, 97, 857-868. [CrossRef] [PubMed]

46. Andries, A.; Daenen, K.; Jouret, F.; Bammens, B.; Mekahli, D.; Schepdael, A.V. Oxidative stress in autosomal dominant polycystic kidney disease: Player and/or early predictor for disease progression? Pediatric Nephrol. 2019, 34, 993-1008. [CrossRef] [PubMed]

47. Kahveci, A.S.; Barnatan, T.T.; Kahveci, A.; Adrian, A.E.; Arroyo, J.; Eirin, A.; Harris, P.C.; Lerman, A.; Lerman, L.O.; Torres, V.E.; et al. Oxidative stress and mitochondrial abnormalities contribute to decreased endothelial nitric oxide synthase expression and renal disease progression in early experimental polycystic kidney disease. Int. J. Mol. Sci. 2020, 21, 1994. [CrossRef] [PubMed]

48. Klawitter, J.; Reed-Gitomer, B.Y.; McFann, K.; Pennington, A.; Klawitter, J.; Abebe, K.Z.; Klepacki, J.; Cadnapaphornchai, M.A.; Brosnahan, G.; Chonchol, M.; et al. Endothelial dysfunction and oxidative stress in polycystic kidney disease. Am. J. Physiol. Ren. Physiol. 2014, 307, F1198-F1206. [CrossRef]

49. Sanchis, I.M.; Shukoor, S.; Irazabal, M.V.; Madsen, C.D.; Chebib, F.T.; Hogan, M.C.; El-Zoghby, Z.; Harris, P.C.; HustoN, J.; Brown, R.D.; et al. Presymptomatic screening for intracranial aneurysms in patients with autosomal polycystic kidney disease. Clin. J. Am. Soc. Nephrol. 2019, 14, 1151-1160. [CrossRef]

50. Hitchcock, E.; Gibson, W.T. A review of the genetics of intracranial berry aneurysms and implications for genetic counseling. J. Genet. Couns. 2017, 26, 21-23. [CrossRef]

51. Rocca, M.S.; Pecile, V.; Cleva, L.; Speltra, E.; Selice, R.; Di Mambro, A.; Foresta, C.; Ferlin, A. The Klinefelter syndrome is associated with high recurrence of copy number variations on the $\mathrm{X}$ chromosome with a potential role in the clinical phenotype. Andrology 2016, 4, 328-334. [CrossRef]

52. Raznahan, A.; Parikshak, N.; Chandran, V.; Blumenthal, J.D.; Clasen, L.S.; Alexander-Bloch, A.F.; Zinn, A.; Wangsa, D.; Wise, J.; Murphy, D.; et al. Sex-chromosome dosage effects on gene expression in humans. Proc. Natl. Acad. Sci. USA 2018, 115, 7398-7403. [CrossRef] [PubMed]

53. Lee, J.T.; Bartolomei, M.S. X-inactivation, imprinting, and long noncoding RNAs in health and disease. Cell 2013, 152, 1308-1323. [CrossRef] [PubMed]

54. Belling, K.; Russo, F.; Jensen, A.B.; Dalgaard, M.D.; Westergaard, D.; Rajpert-De Meyts, E.; Skakkebæk, N.E.; Juul, A.; Brunak, S. Klinefelter syndrome comorbidities linked to increased X chromosome gene dosage and altered protein interactome activity. Hum. Mol. Genet. 2017, 26, 1219-1229. [CrossRef] [PubMed]

55. Sakurai, T.; Iwabuchi, S.; Ueda, M.; Samejima, H.; Saito, E. A Case of subarachnoid hemorrhage due to a ruptured aneurysm with systemic lupus erythematosus and Klinefelter syndrome. Jpn. J. Neurosurg. 2000, 9, 702-706. [CrossRef]

56. Delicado, A.; Lapunzina, P.; Palomares, M.; Molina, M.A.; Galán, E.; Pajares, I.L. Beckwith-Wiedemann syndrome due to 11p15.5 paternal duplication associated with Klinefelter syndrome and a "de novo" pericentric inversion of chromosome Y. Eur. J. Med. Genet. 2005, 48, 159-166. [CrossRef]

57. Peces, R.; Venegas, J.L. Seminal vesicle cysts and infertility in autosomal dominant polycystic kidney disease. Nefrologia 2005, 25, 78-80.

58. Vora, N.; Perrone, R.; Bianchi, D.W. Reproductive issues for adults with autosomal dominant polycystic kidney disease. Am. J. Kidney Dis. 2008, 51, 307-318. [CrossRef]

59. Torra, R.; Sarquella, J.; Calabia, J.; Martí, J.; Ars, E.; Fernández-Llama, P.; Ballarin, J. Prevalence of cysts in seminal tract and abnormal semen parameters in patients with autosomal dominant polycystic kidney disease. Clin. J. Am. Soc. Nephrol. 2008, 3 , 790-793. [CrossRef] 
60. Peces, R.; de la Torre, M.; Urra, J.M. Pituitary-testicular function in cyclosporin-treated renal transplant patients. Nephrol. Dial. Transplant. 1994, 9, 1453-1455. [CrossRef]

61. Posey, J.E.; Harel, T.; Liu, P.; Rosenfeld, J.A.; James, R.A.; Akdemir, Z.H.C.; Walkiewicz, M.; Bi, W.; Xiao, R.; Ding, Y.; et al Resolution of disease phenotypes resulting from multilocus genomic variation. N. Engl. J. Med. 2017, 376, 21-31. [CrossRef]

62. Dixon, J.R.; Gorkin, D.U.; Ren, B. Chromatin Domains: The Unit of Chromosome Organization. Mol. Cell 2016, 62, 668-680. [CrossRef] [PubMed]

63. Gall, E.C.-L.; Chebib, F.T.; Madsen, C.D.; Senum, S.; Heyer, C.M.; Lanpher, B.C.; Patterson, M.C.; Albright, R.C.; Yu, A.S.; Torres, V.E.; et al. The value of genetic testing in polycystic kidney diseases illustrated by a family with PKD2 and COL4A1 mutations. Am. J. Kidney Dis. 2018, 72, 302-308. [CrossRef] [PubMed]

64. Zhang, Y.; Dai, Y.; Raman, A.; Daniel, E.; Metcalf, J.; Reif, G.A.; Pierucci-Alves, F.; Wallace, D.P. Overexpression of TGF- $\beta 1$ induces renal fibrosis and accelerates the decline in kidney function in polycystic kidney disease. Am. J. Physiol. Ren. Physiol. 2020, 319, F1135-F1148. [CrossRef] [PubMed]

65. Fragiadaki, M.; Macleod, F.M.; Ong, A.C.M. The controversial role of fibrosis in autosomal dominant polycystic kidney disease. Int. J. Mol. Sci. 2020, 21, 8936. [CrossRef]

66. Lefèvre, N.; Corazza, F.; Valsamis, J.; Delbaere, A.; De Maertelaer, V.; Duchateau, J.; Casimir, G. The number of X chromosomes influences inflammatory cytokine production following Toll-like receptor stimulation. Front. Immunol. 2019, 10, 1052. [CrossRef]

67. Salemi, M.; Cimino, L.; Marino, M.; Cannarella, R.; Condorelli, R.A.; Romano, C.; La Vignera, S.; Calogero, A.E. Next Generation Sequencing expression profiling of mitochondrial subunits in men with Klinefelter syndrome. Int. J. Med. Sci. 2018, $15,31-35$. [CrossRef]

68. Shukoor, S.S.; Vaughan, L.E.; Edwards, M.E.; Lavu, S.; Kline, T.L.; Senum, S.R.; Mkhaimer, Y.; Zaatari, G.; Irazabal, M.V.; Neal, R.; et al. Characteristics of patients with end-stage kidney disease in ADPKD. Kidney Int. Rep. 2021, 6, 755-767. [CrossRef]

69. Li, D.; Sun, L. MicroRNAs and polycystic kidney disease. Kidney Med. 2020, 2, 762-770. [CrossRef]

70. Di Palo, A.; Siniscalchi, C.; Salerno, M.; Russo, A.; Gravholt, C.H.; Potenza, N. What microRNAs could tell us about the human X chromosome. Cell Mol. Life Sci. 2020, 77, 4069-4080. [CrossRef]

71. Lakshmipathi, J.; Gao, Y.; Hu, C.; Stuart, D.; Genzen, J.; Ramkumar, N.; Kohan, D.E. Nephron-specific disruption of polycystin-1 induces cyclooxygenase-2-mediated blood pressure reduction independent of cystogenesis. J. Am. Soc. Nephrol. 2020, 31, 1243-1254. [CrossRef]

72. Verschuren, E.H.J.; Mohammed, S.G.; Leonhard, W.N.; Overmars-Bos, C.; Veraar, K.; Hoenderop, J.G.J.; Bindels, R.J.M.; Peters, D.J.M.; Arjona, F.J. Polycystin-1 dysfunction impairs electrolyte and water handling in a renal precystic mouse model for ADPKD. Am. J. Physiol. Ren. Physiol. 2018, 31, F537-F546. [CrossRef]

73. Skakkebæk, A.; Viuff, M.; Nielsen, M.M.; Gravholt, C.H. Epigenetics and genomics in Klinefelter syndrome. Am. J. Med. Genet. C Semin. Med. Genet. 2020, 184, 216-225. [CrossRef] 